\title{
Femur fractures and treatment options in 20 dogs admitted to our clinic from January 2013 to December 2015
}

\author{
M. Abd El Raouf*, N.H.M. Mekkawy and A.M. AbdEl-Aal \\ Department of Surgery, Anesthesiology, and Radiology, Faculty of Veterinary Medicine, Zagazig University, Egypt \\ *Corresponding Author: dr_mustafa13@yahoo.com
}

(Received August 18, 2017; Accepted September 29, 2017)

\begin{abstract}
The aim of the present study was to evaluate treatment of 20 dogs with femur fractures. Twenty (20) dogs with different ages, breeds, and gender admitted to the clinic of Department of Surgery, Anesthesiology and Radiology-Faculty of Veterinary Medicine-Zagazig University from January 2013 to December 2015 with a complaint of hind limb lameness and were diagnosed as femur fractures through clinical and radiographic examination. German shepherd dogs $(85 \%)$ and immature dogs $(70 \%)$ were more susceptible to femur fractures. The most common site of the fracture was the femoral diaphysis $(65 \%)$ followed by metaphysis (20\%). Open reduction and internal fixation techniques were applied using intramedullary (IM) pins with or without cerclage wire $(40 \%)$ and bone plate $(15 \%)$ for treatment of diaphyseal fractures, and two cross pins $(30 \%)$ for treatment of metaphyseal and distal physeal fractures. Pin migration after complete healing ( 1 case) and bone re-fracture due to jumping ( 1 case) was the postoperative complications. It was concluded that open reduction and internal fixation methods are the proper treatment for femur fractures if the proper surgical techniques were applied.
\end{abstract}

Keywords: dogs, internal fixation, IM pins, bone plate Available online at http:// www.vetmedmosul.org/ijvs
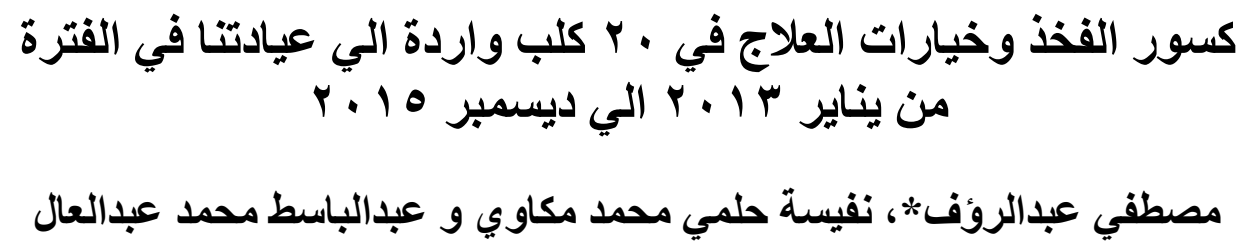

$$
\text { قسم الجر احة والتخدير والأشعة، كلية الطب البيطري، جامعة الزقازيق، مصر }
$$

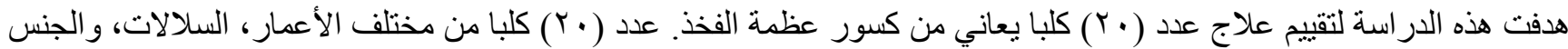

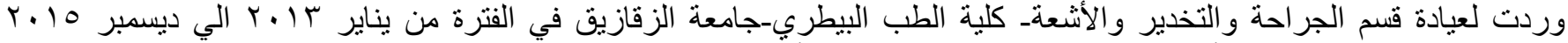

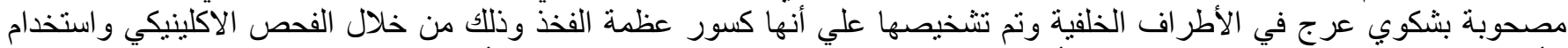

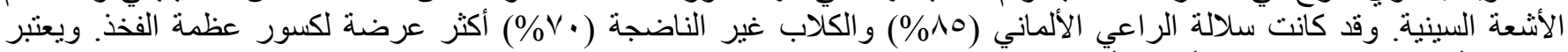

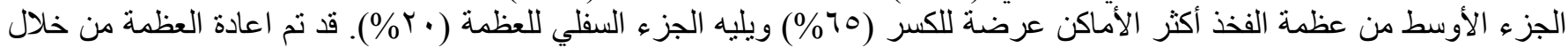

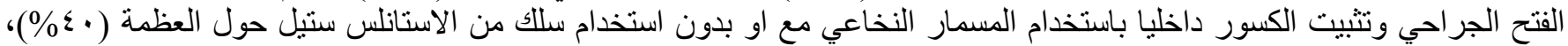

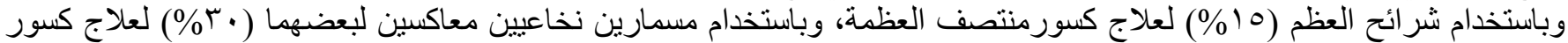

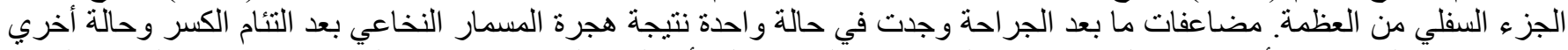

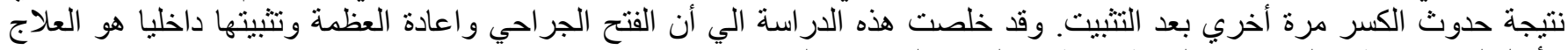
الأمثل لكسور عظمة الفخذ في حالة تطبيق طرق العلاج الجر احية الصحيحة. 


\section{Introduction}

Bone fractures constitute a major problem in small animal practice particularly in dogs (1). Fractures of the long bones are the most common injury in dogs and cats and the femur fractures represent a half of all long bone fractures (2). Violent trauma with vehicular accident or minimal trauma with pathological condition such as neoplasia usually the common causes of fractures (3-5). Femur fracture evaluation is an important point for proper treatment. Fracture should be assessed for type of the fracture, direction of fragments, location of the fracture, whether open or closed, and joint involvement (3).

Restoration of the structure, composition and function of the fractured part is the goal of the fracture treatment. The intrinsic and extrinsic forces generated on the fracture part must be neutralized by fixation method and the structural properties of the bone being restored its normal phase (3,6-10). Femur fractures are not amenable to conservative treatment, and internal fixation is required. Open reduction and fixation is usually performed successfully if basic principles of fracture repair are used $(3,6,7,11,12)$. Closed reduction is rarely possible but the anatomical relationship to the abdominal flank and pelvis prevents adequate immobilization of the hip joint. Furthermore, most of femur fractures are advised to be treated surgically with appropriate fixation technique depending on type of the fracture $(13,14)$.

Various reconstruction methods used for management of femur fractures in dogs including IM pins, bone plate, external skeletal fixation (ESF), lag screw, and interlocking nail (ILN) $(15,16)$. Selection of the proper fixation method depends upon familiarity of the surgeon to fixation technique and equipment, configuration of the fracture, animal age and size, concurrent soft tissue injuries and number of involved limbs (8). Therefore, the aim of the present study was to evaluate treatment of 20 dogs with different fixation methods including IM pins, bone plate with or without cerclage wire and cross pins according to type of the fracture, owner acceptance and facilities and dog size and age.

\section{Materials and methods}

\section{Animals}

A total of 20 dogs with different ages, breeds and gender were admitted to the clinic of Department of Surgery, Anesthesiology and Radiology- Faculty of Veterinary Medicine-Zagazig University with a history of hind limb lameness.

\section{History and clinical examination}

The clinical history and examination were performed firstly by inspection to assess the posture, gait and inflammatory signs (swelling and redness), then by local manipulation to detect animal pain at the affected thigh, abnormal movement and crepitus at the affected femur.

\section{Radiographic examination}

Prior to radiographic examination, the animals were sedated with intramuscular (I/M) injection of $1 \mathrm{mg} / \mathrm{Kg} \mathrm{B}$ wt xylazine hydrochloride 2\% (Xyla-Ject $^{\circledR}$, ADWIA Co. S.A.E. $10^{\text {th }}$ of Ramadan City, Egypt). Anterio-posterior (AP) and medio-lateral (ML) radiographs of the pelvis and thigh region of the affected limb were taken for each animal using X-ray machine (POX-300 BT, TOSHIBA, ROTANODETM, Japan). Appropriate exposure factors were selected based on the weight and thickness of the affected animal. The radiographic images were then interpretated for surgical decision.

\section{Surgical treatment and postoperative management}

Following clinical and radiographic examinations, it was decided to treat fractures with open reduction and internal fixation in cases who their owners accept treatment options. Each animal was premedicated with $\mathrm{I} / \mathrm{M}$ injection of $1 \mathrm{mg} / \mathrm{Kg} \mathrm{B}$ wt xylazine hydrochloride 2\%. General anesthesia was conducted with intravenous (I/V) injection of thiopental sodium 2.5\% (Thiopental Sodium, E.I.P.I.Co $10^{\text {th }}$ of Ramadan City, Egypt) until the main reflexes were disappeared and maintained by repeated $\mathrm{I} / \mathrm{V}$ injection of $2.5 \%$ thiopental sodium with a total dose of $20 \mathrm{mg} / \mathrm{Kg} \mathrm{B}$ wt. All fractures were treated with standard surgical procedure of the femur under complete a septic techniques (5). Open reduction with different internal fixation techniques including IM pins, cross pins, bone plate and cerclage wire if needed were performed according to the type and site of fractures. Supportive bandages were applied for one week after surgeries to provide additional support and limit the movements of the animals. Postoperatively, immediate radiographs were taken for the treated animals. Follow up of the treated cases was done by calling the owners for any complications and healing progress or bringing the animals to the clinic if possible and taking additional radiographs. However, most of owners did not bring their cases to the clinic after surgeries.

\section{Results}

The results of the present study showed that the all animals revealed non weight bearing lameness with a history of trauma from one to four days and swollen thigh muscle. Manipulation of the affected part revealed severe pain with abnormal crepitus. The femoral fractures were more common in German shepherd (85\%), Doberman pinscher $(5 \%)$, White Griffon $(5 \%)$, and non-descriptive dogs $(5 \%)$. The femoral fractures were more common in males $(70 \%)$ than females $(30 \%)$ and in immature dogs 
below one year $(70 \%)$ than mature dogs $(30 \%)$. The right femur was more affected $(65 \%)$ with high incidence of closed fracture $(95 \%)$, only one case suffered from open fracture. According to the history, all fractures occurred due to trauma either fallen from height (from higher floors, during playing or jumping) (55\%) or car accident (45\%). According to the site of the fracture on the bone, diaphyseal fractures $(65 \%)$, metaphyseal fractures $(20 \%)$, distal physeal fractures $(10 \%)$, and capital physeal fracture $(5 \%)$ were diagnosed. According to the fracture line, transverse $(55 \%)$, comminuted $(15 \%)$, multiple $(15 \%)$, short oblique $(10 \%)$, and long oblique $(5 \%)$ fractures were reported.

Seventeen (17) cases were treated with open reduction and different internal fixation techniques and three owners (two cases with diaphyseal fractures and one case with capital physeal fracture) did not accept the treatment advice due to fear from surgical operation. Diaphyseal fractures were treated using IM pin with or without cerclage wire (40\%) (Fig. 1\&2) and bone plate (15\%) (Fig. 3). The metaphyseal and distal physeal fractures were treated using two cross pins (30\%) (Fig. 4). The follow up of the treated cases either by calling the owners or bringing their operated dogs to our clinic and performing radiographs revealed early usage of the treated limbs with bone plate within 4 days after surgery in comparison to those treated with IM pins (from 10 days after surgery). Complications were reported in 2 cases; pin migration after complete healing 2.5 months after surgery and treated with pin removal in one case (Fig. 5a) and bone re-fracture due to jumping in one case (Fig. 5b).
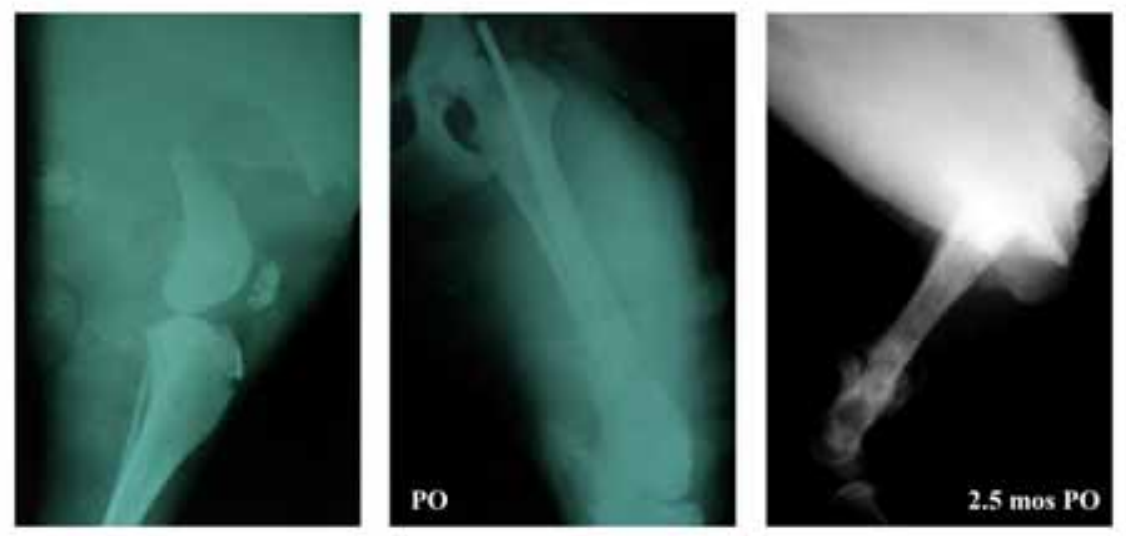

Figure 1: Female German shepherd dog of 8 months age suffered from complete, multiple, overlapping, diaphyseal fracture of the left femur surgically treated and fixed with two IM pins $(3 \mathrm{~mm}$ in diameter). Complete healing of the fracture and pin removal after 2.5 months.
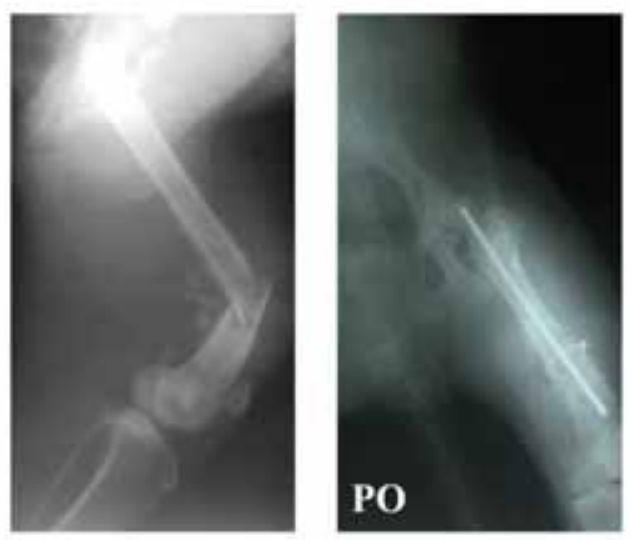

Figure 2: Male German shepherd Dog of 12 months age suffered from complete, impacted, short oblique, diaphyseal fracture of the right femur surgically treated and fixed with IM pin ( $3 \mathrm{~mm}$ in diameter) and cerclage wire $(0.6 \mathrm{~mm}$ in diameter).
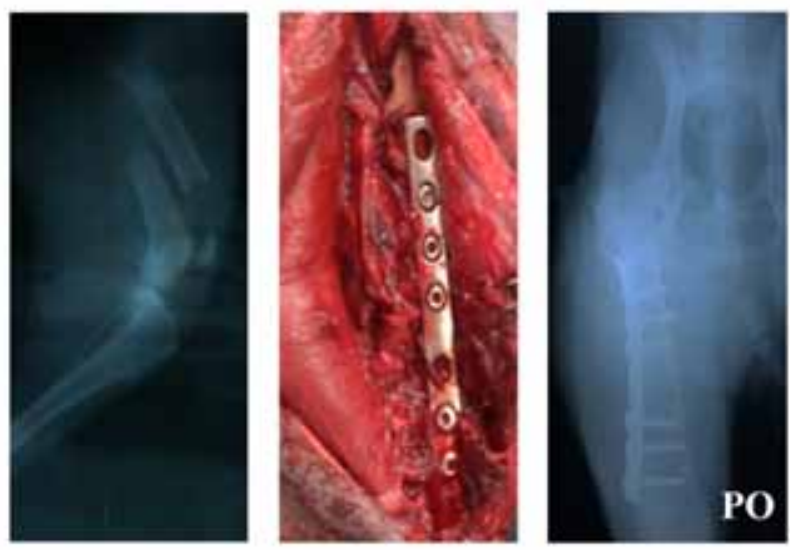

Figure 3: Male German shepherd Dog of 18 months age suffered from complete, overlapping, transverse, diaphyseal fracture of the right femur surgically treated and fixed with $4.5 \mathrm{~mm} \varnothing$ dynamic compression plate (DCP). 

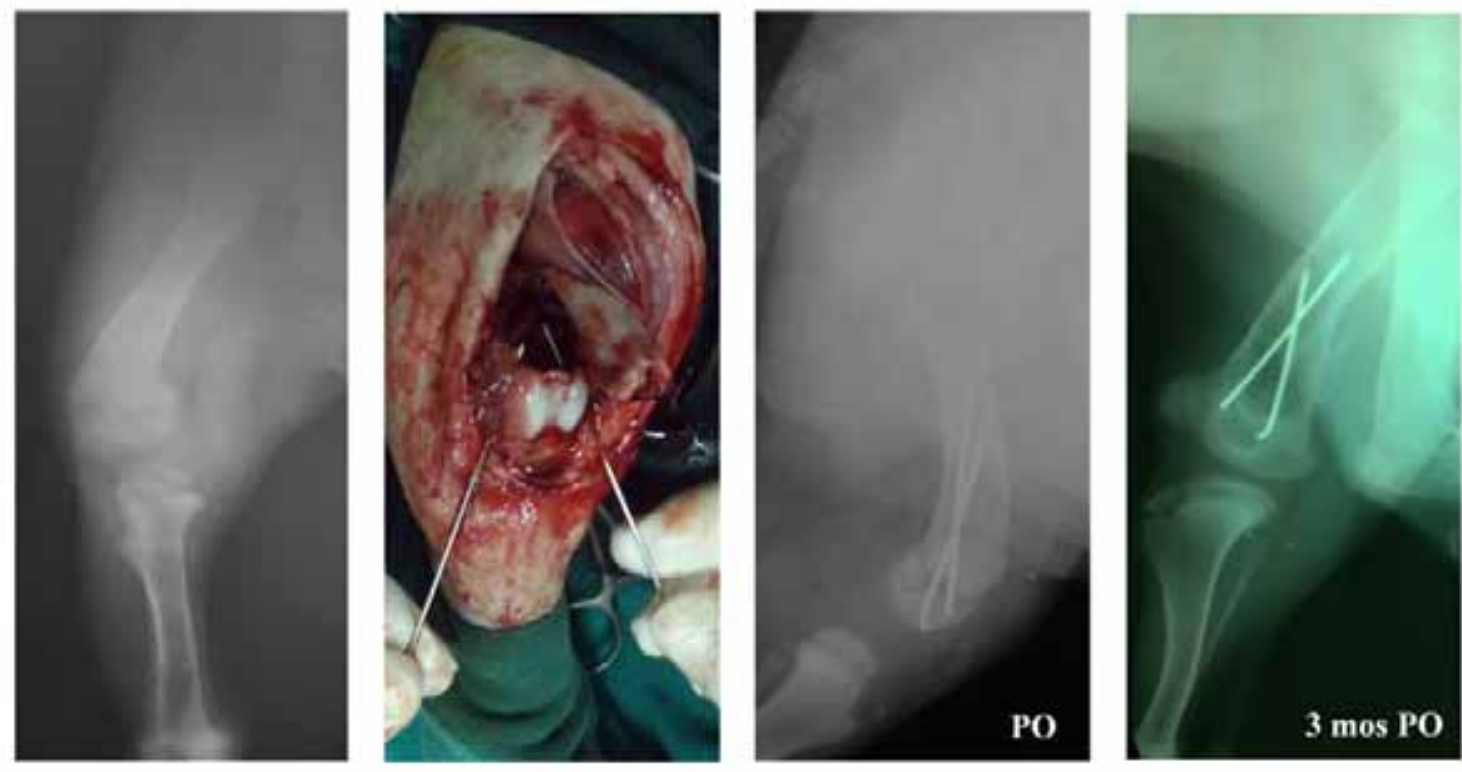

Figure 4: Male puppy of 2 months age suffered from distal physeal fracture of the right femur surgically treated and fixed with two cross pins ( $1.5 \mathrm{~mm}$ in diameter). Complete healing of the fracture after 3 months.
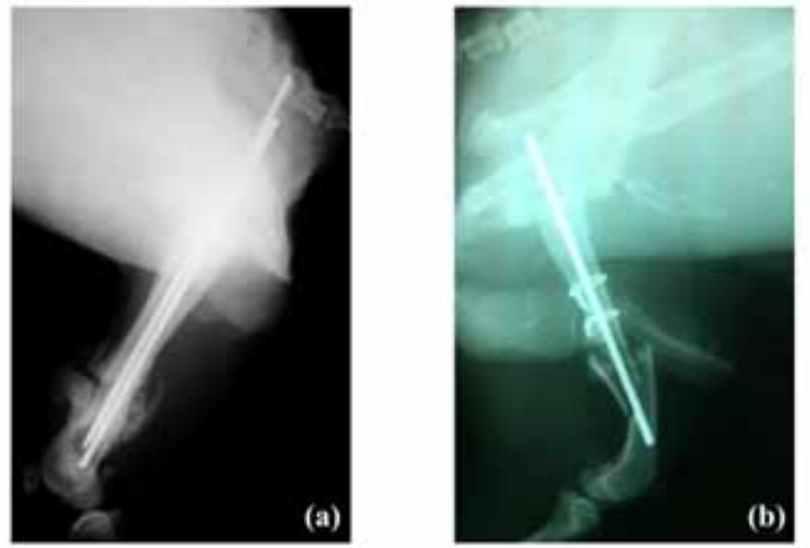

Figure 5: Female German shepherd dog of 8 months of age after 2.5 months from fixation complicated with IM pin migration and treated with pin removal (a), and male white griffon dog complicated with bone re-fracture after one week from fixation due to jumping (b).

\section{Discussion}

The incidence of fractures in dogs was increased in recent years at our clinic, might be due to increasing dog population and more awareness among owners to the veterinary services available. Long bone fractures are considered the most common orthopedic condition among dog population especially in growing dogs $(17,18)$. The femur fractures are the most commonly long bone fractures representing almost half of all long bone fractures $(3,5,10,11,14,15)$. The highest incidence of femoral fractures in German shepherd dogs observed in the present study might be due to increased interest of our population in keeping this breed of dogs. The femur fractures were reported to be the most common skeletal condition affecting growing dogs $(11,15,19)$. This might be due to weight bearing stress or increased forces, in addition to its normal anatomical position with geometric variation in the length of the bone (20) and their bones are more fragile than the older ones (19). It was reported previously that $69 \%$ of femur fractures occurred at or below 2 years of age $(11,21)$. In the present study, $70 \%$ of the femur fractures were observed in dogs below one year of age. Our results were in line with the previously reported $(15,19,21,22)$ that the femur fractures were more common in males than females, $70 \%$ to $30 \%$ respectively. This might be attributed to the high metabolic activity of males than females or the aggressive nature and wandering habits of males making them more susceptible to accidents and fractures. In the present study the right leg fractures were more common than the left one. These results were in contrast with the previously reported $(11,19,22)$ that the left leg was fractured slight more than the right leg. The results of the present study were in line with the previously reported $(3,15,17,23)$ that the direct cause of fractures in the growing dogs was the road traffic accident or fall from height. Femur fractures were observed mostly as closed fractures $(95 \%)$ due to the heavy overlying muscle. This result was in 
accordance with the previously described $(3,11,19)$. Only one case observed with open fracture, this might be due to rough manipulation of the comminuted fracture after traffic injury. Our results were in agreement with the previously reported $(3,22)$ that the diaphyseal and metaphyseal fractures of the femur occurred more commonly in mature dogs while proximal and distal physeal fractures were more common in immature dogs. This might be attributed to the weakness of metaphysis and epiphysis of long bones in growing dogs and the great stress on the distal diaphysis during fall or injury $(15,23)$.

Open reduction with internal fixation was very essential for proper repair of the femur fractures $(3,6,7,11-13)$. Different internal fixation techniques used for treatment of femur fractures including IM pins, bone plate and screws, ESF, lag screws, plate-rod construct and ILN $(3,10,15,16,23)$. The aim of these fixation techniques was to promote fracture stability with significant reduction in local strain at the fracture site (24). IM pins is the most common method of stabilization of the femur fractures $(19,25-29)$. IM pins provides an axial alignment and resists bending forces occurred on the bone during weight bearing but do not have any effect on the shear or rotational forces at the fracture site and additional stabilization devices may be needed to overcome these forces in many types of fractures (30-32). It was reported that IM pins are satisfactory for the shaft of the femur in small dogs (33), but the bone plate gives better results in the medium and large dogs (17). Bone plating resists the rotational, compression, tension and shearing forces in addition to resistance of bending forces (34). In the present study, most of femur fractures were fixed with IM pins and bone plates with or without cerclage wire. The metaphyseal and epiphyseal fractures in the present study were treated with cross pins to provide stability and fracture union as previously reported (5). Osteomyelitis, delayed union, malunion, nonunion, pin migration, quadriceps contracture and damaged soft tissues were the most common reported complications of fracture treatment (34-36). In the present study, one case with pin migration after 2.5 months of treatment was treated with pin removal and one case was re-fractured after treatment were reported as complications with IM pins treatment.

\section{Conclusion}

From the results of the present study, it was concluded that the growing dogs less than 1 year of age were more prone to femur fractures than mature dogs. Open reduction with IM pins fixation were the most common method of fracture fixation as it is safe, inexpensive and successful if the basic principles of fracture repair are used. Bone plates are ideally suited for complex or stable fractures of the femur when prolonged healing is anticipated or when optimal postoperative limb function is desirable. Important factors including appropriate surgical technique, adequate reduction and stabilization, appropriate choice of fixation method, preservation of soft tissues and proper postoperative care. Fracture complications are a reality of fracture repair but the surgeon can minimize the complications incidence.

\section{References}

1. Gadallah S, Marzok M, El-Husseiny I. Fractures repairs in Dogs. Kafrelsheikh Vet Med J. 2009;7 (1):314-336.

2. Unger M, Montavon PM, Heim UF. Classification of fractures of the long bones in the dog and cat: Introduction and clinical application. Vet Comp Orthop Traumatol. 1990;3 (2):5 - 14.

3. Beale B. Orhtopedic clinical techniques femur fracture repair. Clin Tech Small Anim Pract. 2004;19 (3):134 -150.

4. Ozsoy S, Altunatmaz K. Treatment of extremity fractures in dogs using external fixators with closed reduction and limited open approach. Vet Med. 2005;48(5):133-140.

5. Fossum TW, Dewey CW, Horn CV, Johnson AL, MacPhail CM, Radlinsky MG, Schulz KS, Willard MD. Small Animal Surgery. $4^{\text {th }}$ ed. ELSIEVER MOSBY; 2013;pp:1033-1199.

6. Brinker WO. Fractures. Canine surgery. $2^{\text {nd }}$ ed. Archibald, Santa Barbara, Calif, American Veterinary Publications; 1974;pp:949-1048.

7. Olmstead ML. Fractures of the femur. In: Brinker WO, Hohn RB, Prieur WD, editors. Manual of internal fixation in small animals. New York: Springer-Verlag; 1984;pp:165-175.

8. Aron DN. Practical techniques for fractures. In: Bojrab MJ, editor. Current techniques in small animal surgery. $4^{\text {th }}$ ed. Philadelphia; 1998;pp: 934-941.

9. Shahar R. Relative stiffness and stress type I and type II external fixators: Acrylic versus stainless - steel connecting bars- a theoretical approach. Vet Surg. 2000;(29):59-69.

10. Harasen G. Common long bone fractures in small animal practice-Part 1. Can Vet J. 2003a; 44: 333-334.

11. Braden TD, Eicker SW, Abdinoor D, Prieur WD. Characteristics of 1000 femur fractures in the dog and cat. Vet Comp Orthop Trauma. 1995;4:38-44.

12. Dueland RT, Berglund L, Vanderby R, Chao EY. Structural properties of interlocking nails, canine femora, and femur-interlocking nail constructs. Vet Surg. 2007;25:386-396.

13. Simpson DJ, Lewis DD. Fractures of femur. In: Slatter D, editor. Textbook of small animal surgery. $3^{\text {rd }}$ ed. Saunders; 2003; pp: $2059-$ 2088

14. Piermattei D, Flo G, DeCamp C. Handbook of Small Animal Orthopedics and Fracture Repair. $4^{\text {th }}$ ed. Saunders Elsiver, USA. 2006.

15. Aithal HP, Singh GR, Bisht GS. Fractures in Dogs: A survey of 402 cases. Indian J Vet Surg. 1999;20 (1):15 -21.

16. Cunningham JL. Textbook of Current orthopaedics. $5^{\text {th }}$ ed. 2001. 457 -464 .

17. Phillips IR. A survey of bone fractures in the dog and cat. J Small Anim Pract. 1979; 20: 661-674.

18. Schwarz PD. Biomechanics of fractures and fracture fixation. Indian Vet Surgery. 1991;6:1-12.

19. Tercanliogu H, Sarierler M. Femur Fractures and Treatment Options in Dogs Which Brought our Clinics. Lucrari Stiiniiifice Medicina Veterinara. 2009; XLII (2): 98-101.

20. Markel MD, Sielman E, Bogdanske JJ. Densitometric properties of long bones in dogs, as determined by use of dual-energy X-ray absorptiometry. Am J Vet Res. 1994;55:1750-1756.

21. Kolata RJ, Kraut NH, Johnston DE. Patterns of trauma in urban dogs and cats: a study of 1,000 cases. J Am Vet Med Assoc. 1974;164: 499502 . 
22. Shiju SM, Ganesh R, Ayyappan S, Rao GD, Kumar RS, Kundave VR, Das BC. Incidence of pelvic limb fractures in dogs: A survey of 478 cases. Vet World. 2010;3(3):120-121.

23. Harasen G. Common long bone fractures in small animal practice-Part 2. Can Vet J. 2003b; 44:503-504.

24. El-Husseiny IN, Mostafa MB, El-Habak AM, Harb HF. Biomechanical Studies on Femoral Fracture Repair fixed By Different Fixation Methods in Dogs. J Amer Sci. 2012;8(1):216-222.

25. Bernarde A, Diop A, Maurel N, Viguier E. An in vitro biomechanical study of bone plate and interlocking nail in a canine diaphyseal femoral fracture model. Vet Surg. 2001;30:397-408.

26. Cechner PE, Knecht CD, Chaffee VW. Fracture repair failure in the dog: A review of 20 dogs. J. Am. Anim Hosp. Assoc. 1977;13: 613.

27. Caywood DD, Wallce LJ, Braden TD. Osteomyelitis in the dog: A review of 67 cases. J Am Vet Med Assoc. 1978; 172 (8): 943 - 946.

28. Smith CW, Schiller AG, Smith AR, Dorner JL. Osteomyelitis in dogRetrospective study. J Am Anim Hosp Assoc. 1978;14 (5):589-592.
29. Hunt JM, Aitken ML, Denny HR, Gibbs C. The complications of diaphyseal fractures in dogs: A review of 100 cases. J small Anim Pract. 1980;21(2): 103-119.

30. Vasseur PB, Paul HA, Crumley L. Evaluation of fixation devices for prevention of rotation in transverse fractures of the canine femoral shaft: An in vitro study. Am J Vet Res. 1984;45:1504-1507.

31. Howard PE. Principels of intramedullary pin and wire fixation. Simm Vet Med Surg. 1991;6 (1):52-67.

32. Hulse DA, Aron DN. Advances in small animal orthopedics. Compedium. 1994;16:831-832.

33. Hill FW. A survey of bone fractures in the cat. J Small Anim Pract. 1977; 18:457-463.

34. Stiffler KS. Internal fracture fixation. Clin Tech Small Anim Pract. 2004;19(3): $105-13$

35. Chandy G, Ganesh TN, Ramani C, Kumar RS. Quadriceps contracture in a dog Indian Vet J. 2007;84 (7):742-743.

36. Jackson LC, Pacchiana PD. Common Complications of Fracture Repair. Clin Tech Small Anim Pract. 2004;19:168-179. 